\title{
Prognostic nutritional index as a predictor of survival in resectable gastric cancer patients with normal preoperative serum carcinoembryonic antigen levels: a propensity score matching analysis
}

Noriyuki Hirahara, Yoshitsugu Tajima, Yusuke Fujii, Shunsuke Kaji, Tetsu Yamamoto, Ryoji Hyakudomi, Takahito Taniura and Yasunari Kawabata

\begin{abstract}
Background: An ideal tumor marker should be capable of being detected at any stage of the disease. However, gastric cancer patients do not always have elevated serum carcinoembryonic antigen (CEA) levels, even in advanced cases. Recently, several studies have investigated the associations between preoperative PNI and postoperative long-term outcomes. In this study, we focused on the significance of the prognostic nutritional index (PNI) as a potential predictor of survival in resectable gastric cancer patients with normal preoperative serum CEA levels.

Methods: We retrospectively conducted cohort study to evaluate the PNI as a predictor of survival in 368 resectable gastric cancer patients who underwent potentially curative gastrectomy at our institute between January 2010 and December 2016. We selected 218 patients by propensity score matching to reduce biases due to the different distributions of co-variables among the comparable groups.

Results: In the multivariate analysis, pStage (hazard ratio [HR]: 14.003, 95\% confidence interval [CI]: 5.033-44. 487; $p<0.001$ ), PNI (HR: 2.794, 95\% Cl: 1.352-6.039; $p<0.001$ ) were identified as independent prognostic factors of CSS in 218 propensity matched gastric cancer patients. The Kaplan-Meier analysis demonstrated that low PNI patients had a significantly poorer cancer specific survival (CSS) than high PNI patients $(p=0.008)$. Among 166 propensity matched gastric cancer patients with normal preoperative serum CEA levels, multivariate analysis demonstrated that pStage (HR: 7.803, 95\% Cl: 3.015-24.041; $p<0.001$ ) and PNI (HR: 3.078, 95\% Cl: $1.232-8.707 ; p=0.016)$ were identified as independent prognostic factors of CSS. And Kaplan-Meier analysis demonstrated that low PNI had a significantly poorer CSS than high PNI value $(p=0.011)$.
\end{abstract}

Conclusions: This study demonstrates that a low preoperative PNI value is a potential independent risk factor for poorer CSS in patients with gastric cancer, even in those with normal serum CEA levels.

Keywords: Gastric cancer, Prognostic nutritional index, Normal CEA, Prognostic factor

\footnotetext{
* Correspondence: norinorihirahara@yahoo.co.jp

Department of Digestive and General Surgery, Shimane University Faculty of

Medicine, 89-1 Enya-cho, Izumo, Shimane 693-8501, Japan
} 


\section{Background}

In recent years, there has been increasing concern regarding the association between the systemic inflammatory response and survival in patients with various types of cancer [1-3]. In addition, the systemic inflammatory response has attracted considerable attention as a unique prognostic factor independent of conventional tumor markers $[4,5]$. Most tumor markers are produced by tumor cells. However, systemic inflammation involves biochemical reactions in response to cancer cell secreted inflammatory cytokines [6]. Cancer-related inflammatory changes induced by hypercytokinemia can be indirectly evaluated using multiple assessment tools (e.g., Glasgow prognostic scores, neutrophil-to-lymphocyte ratios, and lymphocyte-to-monocyte ratios) [7, 8]. Several studies have investigated the associations between preoperative nutritional status, cancer-related inflammation, and postoperative long-term outcomes. However, there is little data on the impact of longterm outcomes in patients undergoing curative laparoscopic gastrectomy for gastric cancer.

An ideal tumor marker should be capable of being detected at any stage of the disease. However, a diagnosis of cancer cannot be made on the basis of tumor markers alone, because the majority of tumor markers lack sufficient sensitivity and specificity. Moreover, in clinical practice, it is not unusual to examine the normal range of tumor markers, even in patients with advanced cancer. Therefore, the establishment of an independent and complementary prognostic indicator other than conventional tumor markers is of great clinical significance. The prognostic nutritional index (PNI) was originally reported as a nutritional assessment tool for predicting the risk of operative morbidity and mortality after gastrointestinal surgery. Only recently has it been identified as an indicator of cancer-related systemic inflammation [9].

In this study, we examine the utility of the PNI as a predictor of survival in the propensity score matched gastric cancer patients with normal preoperative serum carcinoembryonic antigen (CEA) levels.

\section{Methods}

\section{Patients}

We retrospectively reviewed a database of medical records from 368 consecutive patients who had undergone potentially curative gastrectomy with R0 resection for histologically confirmed gastric adenocarcinoma at our institute between January 2010 and December 2016. We performed propensity score matching using $\mathrm{R}$ version 3.1.3 software to reduce biases due to the different distributions of covariables among the comparable groups; grouping variable was depth of tumor, lymph node metastasis, and pathological stage.

R0 resection was defined as a complete resection without any microscopic resection margin involvement. Laparoscopic or laparoscopy-assisted gastrectomy was performed in all patients. The extent of gastrectomy and lymph node dissection was in accordance with the Japanese Gastric Cancer Treatment Guidelines (Version 3) [10]. The patients' clinical characteristics, laboratory data, treatment, and pathological data were obtained from medical records. Among the patients with gastric adenocarcinoma, 166 had normal preoperative serum CEA levels $(<5 \mathrm{ng} / \mathrm{ml})$.

All participants provided informed written consent. This study's retrospective design was approved by the Institutional Review Board Committee and was in accordance with the Helsinki Declaration.

\section{Preoperative nutritional parameters}

All laboratory data used for calculating preoperative nutritional parameters were obtained within 1 week before surgery. The following items were selected as concise constitutional evaluation methods: body mass index $(\mathrm{BMI})=$ body weight $(\mathrm{kg}) /$ height $\left(\mathrm{m}^{2}\right)$ and the $\mathrm{PNI}=10 \times$ serum albumin $\quad(\mathrm{g} / \mathrm{dl})+0.005 \times$ total lymphocyte count $\left(/ \mathrm{mm}^{3}\right)$ in peripheral blood [9].

A receiver operating characteristic curve of the preoperative PNI was generated for the multiple logistic regression analysis of cancer-specific survival (CSS). The

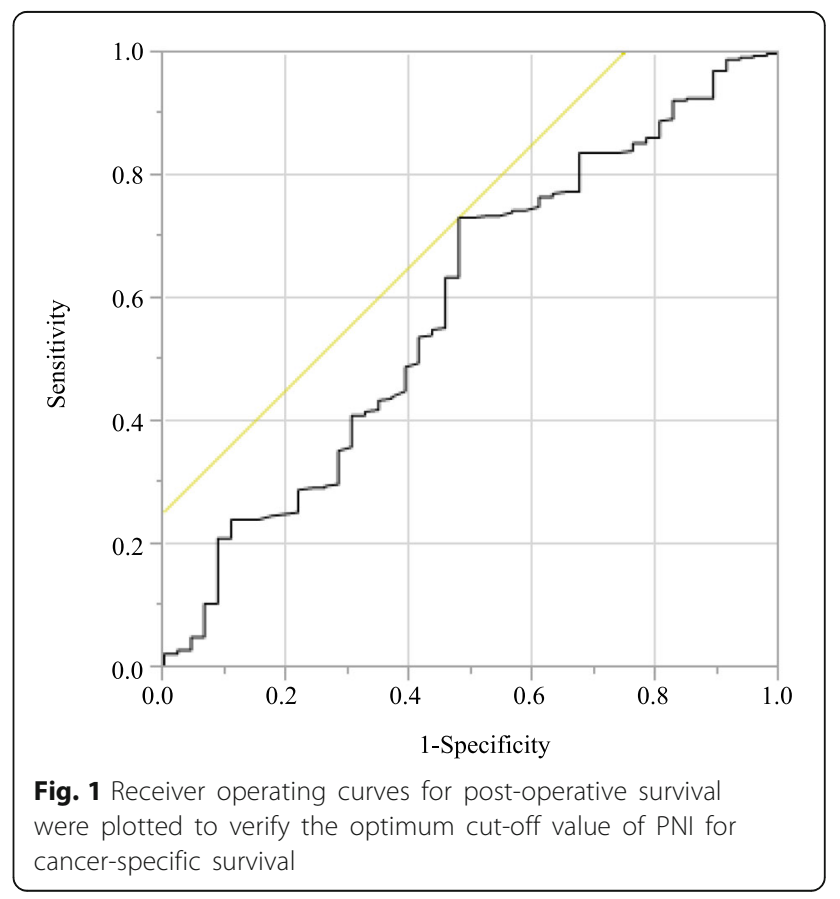


Table 1 Relationships between PNI and clinicopathological features in overall gastric cancer patients before and after propensity score matching

\begin{tabular}{|c|c|c|c|c|c|c|c|c|}
\hline \multirow{4}{*}{ Characteristics } & \multirow{4}{*}{$\begin{array}{l}\text { Total } \\
\text { patients }\end{array}$} & \multirow{2}{*}{\multicolumn{3}{|c|}{$\begin{array}{l}\text { All patients } \\
\text { PNI }\end{array}$}} & \multirow{4}{*}{$\begin{array}{l}\text { Total } \\
\text { patients }\end{array}$} & \multirow{2}{*}{\multicolumn{3}{|c|}{$\begin{array}{l}\text { Propensity matched patients } \\
\text { PNI }\end{array}$}} \\
\hline & & & & & & & & \\
\hline & & $<44.3$ & $\geq 44.3$ & & & $<44.3$ & $\geq 44.3$ & \\
\hline & & $(n=109)$ & $(n=259)$ & $p$ value & & $(n=109)$ & $(n=109)$ & $p$ value \\
\hline \multicolumn{2}{|l|}{ Age (years) } & $75.8 \pm 9.2$ & $68.5 \pm 11.2$ & $<0.001$ & & $75.8 \pm 9.2$ & $68.3 \pm 11.0$ & $<0.001$ \\
\hline \multicolumn{2}{|l|}{ Sex } & & & 0.124 & & & & 0.315 \\
\hline Male & 254 & 69 & 185 & & 145 & 69 & 76 & \\
\hline Female & 114 & 40 & 74 & & 73 & 40 & 33 & \\
\hline \multicolumn{2}{|l|}{ BMI } & $21.45 \pm 3.42$ & $22.85 \pm 3.41$ & $<0.001$ & & $21.45 \pm 3.42$ & $22.61 \pm 3.13$ & 0.009 \\
\hline \multicolumn{2}{|l|}{ WBC $(\mu l)$} & $5416.8 \pm 1464.3$ & $5877.0 \pm 1342.9$ & 0.004 & & $5416.8 \pm 1464.3$ & $6050.1 \pm 1407.6$ & 0.001 \\
\hline \multicolumn{2}{|l|}{$\mathrm{RBC}(\times 104 \mu \mathrm{l})$} & $365.8 \pm 55.9$ & $465.1 \pm 356.3$ & 0.004 & & $365.8 \pm 55.9$ & $470.4 \pm 432.3$ & 0.013 \\
\hline \multicolumn{2}{|c|}{ Location of tumor } & & & 0.187 & & & & 0.333 \\
\hline EGJ & 11 & 2 & 9 & & 6 & 2 & 4 & \\
\hline$U$ & 70 & 23 & 47 & & 41 & 23 & 18 & \\
\hline M & 162 & 40 & 122 & & 91 & 40 & 51 & \\
\hline L & 125 & 44 & 81 & & 80 & 44 & 36 & \\
\hline \multicolumn{2}{|c|}{ Tumor size (mm) } & $60.37 \pm 33.40$ & $41.89 \pm 28.74$ & $<0.001$ & & $60.37 \pm 33.40$ & $48.06 \pm 32.05$ & $<0.006$ \\
\hline \multicolumn{2}{|l|}{ Procedure } & & & 0.090 & & & & 0.954 \\
\hline LTG & 82 & 31 & 51 & & 60 & 31 & 29 & \\
\hline LPG & 37 & 7 & 30 & & 14 & 7 & 7 & \\
\hline$L(A) D G$ & 249 & 71 & 178 & & 144 & 71 & 73 & \\
\hline \multicolumn{2}{|l|}{ Differentiation } & & & 0.123 & & & & 0.919 \\
\hline Well & 71 & 14 & 57 & & 27 & 14 & 13 & \\
\hline Moderate & 134 & 42 & 92 & & 82 & 42 & 40 & \\
\hline Poor & 163 & 53 & 110 & & 109 & 53 & 56 & \\
\hline \multicolumn{2}{|l|}{ Depth of tumor } & & & $<0.001$ & & & & 0.937 \\
\hline T1a-1b & 190 & 40 & 150 & & 80 & 40 & 40 & \\
\hline 2 & 48 & 12 & 36 & & 27 & 12 & 15 & \\
\hline 3 & 54 & 23 & 31 & & 45 & 23 & 22 & \\
\hline $4 a-4 b$ & 74 & 34 & 40 & & 66 & 34 & 32 & \\
\hline \multicolumn{3}{|c|}{ Lymph node metastasis } & & 0.010 & & & & 0.813 \\
\hline NO & 244 & 59 & 185 & & 120 & 59 & 61 & \\
\hline N1 & 40 & 14 & 26 & & 30 & 14 & 16 & \\
\hline N2 & 42 & 19 & 23 & & 33 & 19 & 14 & \\
\hline N3 & 42 & 17 & 25 & & 35 & 17 & 18 & \\
\hline \multicolumn{2}{|c|}{ Pathological stage } & & & $<0.001$ & & & & 0.963 \\
\hline $1 a-1 b$ & 217 & 45 & 172 & & 92 & 45 & 47 & \\
\hline $2 a-2 b$ & 65 & 26 & 39 & & 51 & 26 & 25 & \\
\hline $3 a-3 c$ & 86 & 38 & 48 & & 75 & 38 & 37 & \\
\hline \multicolumn{2}{|c|}{ Operation time (min) } & $416.1 \pm 126.0$ & $419.5 \pm 116.3$ & 0.804 & & $416.1 \pm 126.0$ & $430.5 \pm 121.2$ & 0.391 \\
\hline \multicolumn{9}{|l|}{ Intraoperative } \\
\hline \multicolumn{2}{|c|}{ blood loss (ml) } & $325.3 \pm 699.0$ & $180.8 \pm 359.9$ & 0.009 & & $325.3 \pm 699.0$ & $257.0 \pm 485.4$ & 0.404 \\
\hline \multicolumn{2}{|c|}{ Albumin (g/dl) } & $3.26 \pm 0.49$ & $4.21 \pm 0.34$ & $<0.001$ & & $3.26 \pm 0.49$ & $4.20 \pm 0.35$ & $<0.001$ \\
\hline \multicolumn{2}{|c|}{$\mathrm{CRP}(\mathrm{mg} / \mathrm{l})$} & $0.705 \pm 1.22$ & $0.190 \pm 0.540$ & $<0.001$ & & $0.705 \pm 1.22$ & $0.205 \pm 0.478$ & $<0.001$ \\
\hline
\end{tabular}


Table 1 Relationships between PNI and clinicopathological features in overall gastric cancer patients before and after propensity score matching (Continued)

\begin{tabular}{|c|c|c|c|c|c|c|c|c|}
\hline \multirow{4}{*}{ Characteristics } & \multirow{4}{*}{$\begin{array}{l}\text { Total } \\
\text { patients }\end{array}$} & \multirow{2}{*}{\multicolumn{3}{|c|}{$\begin{array}{l}\text { All patients } \\
\text { PNI }\end{array}$}} & \multirow{4}{*}{$\begin{array}{l}\text { Total } \\
\text { patients }\end{array}$} & \multirow{2}{*}{\multicolumn{3}{|c|}{$\begin{array}{l}\text { Propensity matched patients } \\
\text { PNI }\end{array}$}} \\
\hline & & & & & & & & \\
\hline & & $<44.3$ & $\geq 44.3$ & & & $<44.3$ & $\geq 44.3$ & \\
\hline & & $(n=109)$ & $(n=259)$ & $p$ value & & $(n=109)$ & $(n=109)$ & $p$ value \\
\hline \multicolumn{2}{|l|}{ CEA (ng/ml) } & & & 0.117 & & & & 0.204 \\
\hline$<5$ & 286 & 79 & 207 & & 166 & 79 & 87 & \\
\hline$>5$ & 82 & 30 & 52 & & 52 & 30 & 22 & \\
\hline \multicolumn{2}{|c|}{ Adjuvant chemotherapy } & & & 0.541 & & & & 0.035 \\
\hline Yes & 100 & 32 & 68 & & 79 & 32 & 47 & \\
\hline No & 268 & 77 & 191 & & 139 & 77 & 62 & \\
\hline
\end{tabular}

area under the curve estimation method was used to assess the ability of the PNI to predict CSS. The optimal cutoff value of the PNI was set at 44.3, based on the 5year postoperative CSS (Fig. 1) (sensitivity, 73.3\%; specificity, 52.2\%; and area under the receiver operating characteristic curve, 0.593). Patients were stratified into a high or low preoperative PNI group based on the cutoff value.

\section{Tumor staging}

The pathological classification of the primary tumor, degree of lymph node involvement, and presence or absence of organ metastasis were determined according to the 7 th edition of the American Joint Committee on Cancer TNM classification system [11].

\section{Statistical analyses}

Quantitative variables were expressed as means \pm standard deviation, while qualitative variables were expressed as numbers and percentages. Differences between the groups were evaluated using the Student's $t$-test. Comparisons between non-normally distributed continuous variables among the three groups were performed using the Kruskal-Wallis test. Differences between the categorical variables were analyzed using the Chi-square test. CSS was calculated using the Kaplan-Meier method and compared by the logrank test. CSS was defined as the time interval between the date of gastrectomy and the date of death from any cause, cancer-specific death, or withdrawal of consent.

Univariate analysis was performed to identify factors associated with CSS. Variables with a $p<0.05$ in the univariate analysis were subjected to multivariate analysis using a Cox proportional hazards model to determine independent prognostic factors. Potential prognostic factors included age ( $<70$ vs. $\geq 70$ years $)$, sex (female vs. male), BMI (<18.5 vs. $\geq 18.5)$, PNI (<
44.3 vs. $\geq 44.3$ ), pathological Stage (pStage I/II vs. III), tumor size $(<5.0$ vs. $\geq 5.0 \mathrm{~cm})$, cancer cell differentiation (well- vs. moderately- and poorly-differentiated), preoperative serum CEA level (<5.0 vs. $\geq 5.0 \mathrm{ng} / \mathrm{ml})$, and postoperative adjuvant chemotherapy ("Yes" vs. "No").

All statistical analyses were conducted using JMP software for Windows, version 11 (SAS Institute, Cary, NC, USA). All tests were two sided, and $p<0.05$ was considered statistically significant.

\section{Results}

Associations between PNI values and clinicopathological characteristics in before and after propensity score matched patients

Associations between the PNI and clinicopathological characteristics of the entire cohort of 368 patients with gastric adenocarcinoma are summarized in Table 1. Based on a PNI cutoff of 44.3, 109 patients $(29.6 \%)$ were included in the low PNI group and 259 patients $(70.4 \%)$ were included in the high PNI group. PNI values were significantly associated with age $(p<0.001)$, BMI $(p<0.001)$, white blood cell counts $(p=0.004)$, red blood cell counts $(p=0.004)$, tumor size and depth $(p<0.001)$, lymph node metastasis $(p=0.010)$, pStage $(p<0.001)$, intraoperative blood loss $(p=0.009)$, serum albumin concentrations $(p<0.001)$, and C-reactive protein levels $(p<0.001)$.

Among high PNI patients 78.2\% (68/87) with stage II and stage III received adjuvant chemotherapy, whereas low PNI patients only 50.0\% (32/64) with stage II and stage III received adjuvant chemotherapy.

After propensity score matching, depth of tumor, lymph node metastasis, and pathological stage did not differ significantly between the low and high PNI groups. Finally, 218 patients were selected for analysis. 


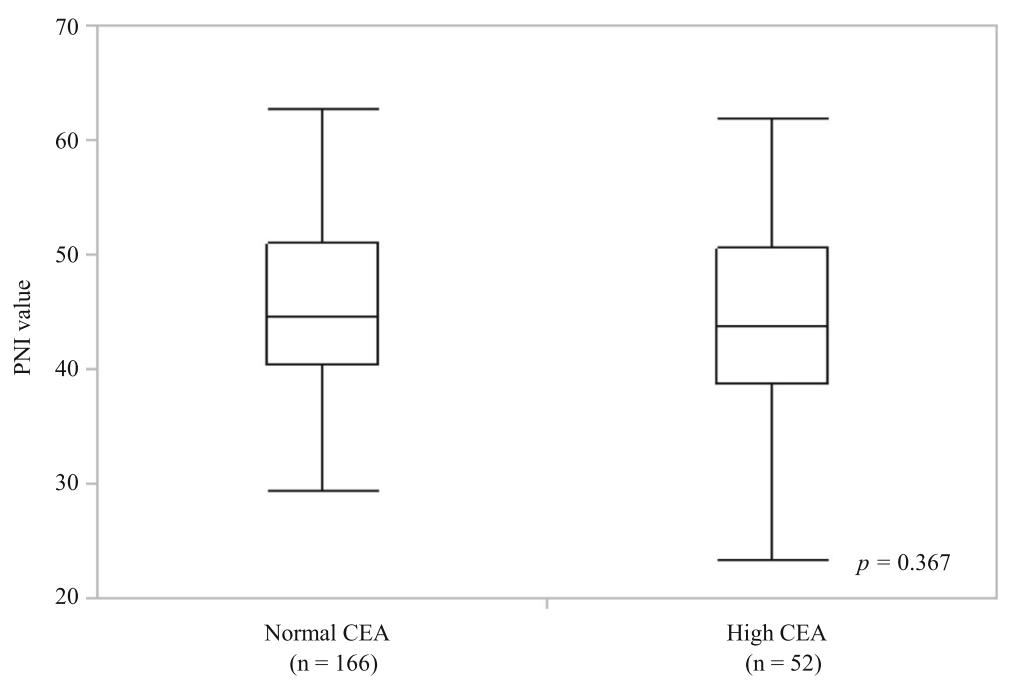

Fig. 2 PNI values in propensity score matched 218 gastric cancer patients according to the serum level of carcinoembryonic antigen. KruskalWallis test: $p=0.367$. In each box plot, the lower and upper ends of the box represent the 25th and 75th percentiles, respectively. Capped bars indicate the minimum and maximum values, respectively, and the line inside the box represents the median PNI value

PNI values and serum CEA levels in the propensity score matched patients

No association between the PNI values and serum CEA levels were detected using a one-way KruskalWallis analysis $(p=0.367)$. The mean PNI values for patients with normal $(n=166)$ and elevated serum CEA levels $(n=52)$ were $45.34 \pm 7.63$ and $44.22 \pm 8.11$, respectively (Fig. 2).

\section{Cox regression analysis of CSS in the propensity score matched patients}

In the univariate analysis, pStage $(p<0.001)$, tumor size $(p=0.025)$, PNI $(p=0.049)$, CEA level $(p=0.040)$, and adjuvant chemotherapy $(p=0.008)$ were significantly associated with CSS. In the multivariate analysis, pStage (hazard ratio [HR]: 14.003, 95\% confidence interval [CI]: 5.033-44.487; $p<0.001$ ), and PNI (HR: 2.794, 95\% CI: 1.352-6.039; $p<0.001)$ were identified as independent prognostic factors of CSS in 218 propensity score matched patients (Table 2).

\section{Survival analysis stratified by the PNI in the propensity score matched patients}

The Kaplan-Meier analysis and log-rank test demonstrated that patients with a low PNI value had a significantly poorer CSS than those with a high PNI value $(p=0.008$; Fig. 3$)$.

Table 2 Univariate and multivariate analyses to assess the prognostic factors in propensity score matched 218 gastric cancer patients

\begin{tabular}{|c|c|c|c|c|c|c|c|}
\hline \multirow[t]{2}{*}{ Variables } & & \multicolumn{3}{|c|}{ Univariate analysis } & \multicolumn{3}{|c|}{ Multivariate analysis } \\
\hline & & $\mathrm{HR}$ & $95 \% \mathrm{Cl}$ & $p$ value & $\mathrm{HR}$ & $95 \% \mathrm{Cl}$ & $p$ value \\
\hline Gender & female / male & 1.414 & $0.690-3.116$ & 0.353 & & & \\
\hline Age & $<70 / \geq 70$ & 0.709 & $0.355-1.410$ & 0.325 & & & \\
\hline pStage & I, II / III & 10.130 & $4.483-27.161$ & $<0.001$ & 14.003 & $5.033-44.487$ & $<0.001$ \\
\hline Tumor size & $<5 / \geq 5$ & 2.263 & $1.107-4.977$ & 0.025 & 1.735 & $0.718-3.910$ & 0.212 \\
\hline PNI & $\geq 44.3 /<44.3$ & 2.000 & $0.999-4.197$ & 0.049 & 2.794 & $1.352-6.039$ & $<0.001$ \\
\hline CEA & $<5.0 / \geq 5.0$ & 2.136 & $1.036-4.254$ & 0.040 & 1.821 & $0.878-3.649$ & 0.105 \\
\hline Diff. & well \& mod / poor & 1.533 & $0.770-3.161$ & 0.226 & & & \\
\hline BMI & $\geq 18.5 /<18.5$ & 1.052 & $0.414-3.548$ & 0.924 & & & \\
\hline Adjuvant & No / Yes & 2.528 & $1.268-5.218$ & 0.008 & 1.052 & $0.485-2.364$ & 0.899 \\
\hline
\end{tabular}




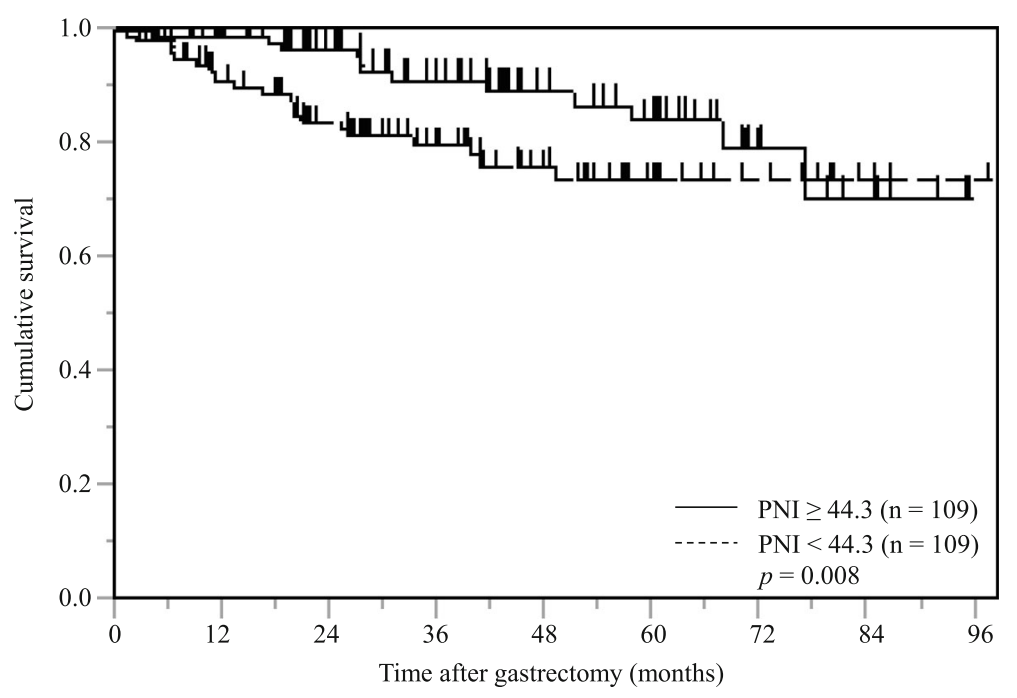

Fig. 3 Kaplan-Meier curves of postoperative cancer-specific survival based on PNI in propensity score matched 218 gastric cancer patients

Survival analysis stratified by the CEA in the propensity score matched patients

The Kaplan-Meier analysis and log-rank test demonstrated that propensity score matched 52 gastric cancer patients with a high serum CEA levels had a significantly poorer CSS than 166 patients with a low CEA levels ( $p=0.029$; Fig. 4$)$.

Associations between PNI values and clinicopathological characteristics in the propensity score matched patients with normal preoperative serum CEA levels

Associations between the PNI and clinicopathological characteristics of the 286 patients with normal preoperative serum CEA levels are summarized in Table 3. Based on a PNI cutoff of 44.3, 79 patients (27.6\%) were included in the low PNI group and 207 patients $(72.4 \%)$ were included in the high PNI group. PNI values were significantly associated with age $(p<0.001)$, BMI $(p=0.003)$, white blood cell counts $(p=0.009)$, red blood cell counts $(p=0.021)$, tumor size $(p<0.001)$, tumor depth $(p=0.001)$, lymph node metastasis $(p=0.032)$, pStage $(p=0.001)$, serum albumin concentrations $(p<0.001)$, and Creactive protein levels $(p<0.001)$.

After propensity score matching, depth of tumor, lymph node metastasis, and pathological stage did not

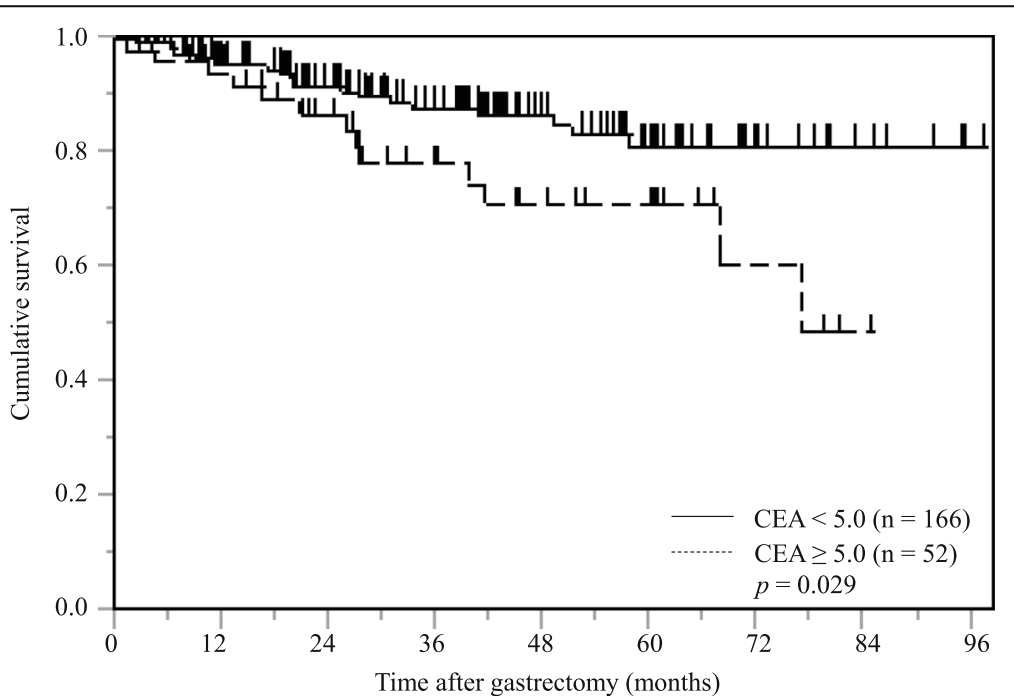

Fig. 4 Kaplan-Meier curves of postoperative cancer-specific survival based on serum CEA levels in propensity score matched 218 gastric cancer patients 
Table 3 Relationships between PNI and clinicopathological features in gastric cancer patients with normal serum CEA levels before and after propensity score matching

\begin{tabular}{|c|c|c|c|c|c|c|c|c|}
\hline \multirow{4}{*}{ Characteristics } & \multirow{4}{*}{$\begin{array}{l}\text { Total } \\
\text { patients }\end{array}$} & \multirow{2}{*}{\multicolumn{3}{|c|}{$\begin{array}{l}\text { All patients } \\
\text { PNI }\end{array}$}} & \multirow{4}{*}{$\begin{array}{l}\text { Total } \\
\text { patients }\end{array}$} & \multirow{2}{*}{\multicolumn{3}{|c|}{$\begin{array}{l}\text { Propensity matched patients } \\
\text { PNI }\end{array}$}} \\
\hline & & & & & & & & \\
\hline & & \multirow{2}{*}{$\begin{array}{l}<44.3 \\
(n=79)\end{array}$} & \multicolumn{2}{|l|}{$\geq 44.3$} & & \multirow{2}{*}{$\begin{array}{l}<44.3 \\
(n=79)\end{array}$} & \multirow{2}{*}{$\begin{array}{l}\geq 44.3 \\
(n=87)\end{array}$} & \multirow[b]{2}{*}{$p$ value } \\
\hline & & & $(n=207)$ & $p$ value & & & & \\
\hline \multicolumn{2}{|l|}{ Age (years) } & $75.2 \pm 9.5$ & $68.1 \pm 11.5$ & $<0.0001$ & & $75.2 \pm 9.5$ & $68.2 \pm 11.5$ & $<0.001$ \\
\hline \multicolumn{2}{|l|}{ Sex } & & & 0.2912 & & & & 0.347 \\
\hline Male & 191 & 49 & 142 & & 109 & 49 & 60 & \\
\hline Female & 95 & 30 & 65 & & 57 & 30 & 27 & \\
\hline \multicolumn{2}{|l|}{ BMl } & $21.45 \pm 3.41$ & $22.80 \pm 3.39$ & 0.0029 & & $21.45 \pm 3.41$ & $22.54 \pm 3.21$ & 0.036 \\
\hline \multicolumn{2}{|l|}{ WBC $(\mu \mathrm{l})$} & $5367.0 \pm 1482.3$ & $5838.3 \pm 1297.8$ & 0.0088 & & $5367.0 \pm 1482.3$ & $5916.4 \pm 1259.0$ & 0.011 \\
\hline \multicolumn{2}{|l|}{$\mathrm{RBC}(\times 104 \mu \mathrm{l})$} & $368.4 \pm 50.2$ & $472.6 \pm 397.5$ & 0.021 & & $368.4 \pm 50.2$ & $479.2 \pm 483.3$ & 0.044 \\
\hline \multicolumn{2}{|c|}{ Location of tumor } & & & 0.5422 & & & & 0.634 \\
\hline EGJ & 9 & 2 & 7 & & 5 & 2 & 3 & \\
\hline$U$ & 48 & 12 & 36 & & 26 & 12 & 14 & \\
\hline M & 132 & 33 & 99 & & 76 & 33 & 43 & \\
\hline L & 97 & 32 & 65 & & 59 & 32 & 27 & \\
\hline \multicolumn{2}{|l|}{ Tumor size (mm) } & $59.86 \pm 31.41$ & $41.06 \pm 29.34$ & $<0.0001$ & & $59.86 \pm 31.41$ & $47.39 \pm 32.81$ & 0.014 \\
\hline \multicolumn{2}{|l|}{ Procedure } & & & 0.2763 & & & & 0.872 \\
\hline LTG & 59 & 19 & 40 & & 43 & 19 & 24 & \\
\hline LPG & 26 & 4 & 22 & & 8 & 4 & 4 & \\
\hline$L(A) D G$ & 201 & 56 & 145 & & 115 & 56 & 59 & \\
\hline \multicolumn{2}{|l|}{ Differentiation } & & & 0.2569 & & & & 0.812 \\
\hline Well & 53 & 10 & 43 & & 20 & 10 & 10 & \\
\hline Moderate & 106 & 33 & 73 & & 66 & 33 & 33 & \\
\hline Poor & 127 & 36 & 91 & & 80 & 36 & 44 & \\
\hline \multicolumn{2}{|l|}{ Depth of tumor } & & & 0.0009 & & & & 0.713 \\
\hline $\mathrm{T} 1 \mathrm{a}-1 \mathrm{~b}$ & 154 & 31 & 123 & & 64 & 31 & 33 & \\
\hline 2 & 37 & 8 & 29 & & 22 & 8 & 14 & \\
\hline 3 & 41 & 16 & 25 & & 33 & 16 & 17 & \\
\hline $4 a-4 b$ & 52 & 24 & 28 & & 47 & 24 & 23 & \\
\hline \multicolumn{2}{|c|}{ Lymph node metastasis } & & & 0.0318 & & & & 0.682 \\
\hline NO & 199 & 46 & 153 & & 98 & 46 & 52 & \\
\hline N1 & 31 & 9 & 22 & & 23 & 9 & 14 & \\
\hline N2 & 30 & 12 & 18 & & 24 & 12 & 12 & \\
\hline N3 & 26 & 12 & 14 & & 21 & 12 & 9 & \\
\hline \multicolumn{2}{|c|}{ Pathological stage } & & & 0.001 & & & & 0.884 \\
\hline $1 a-1 b$ & 178 & 36 & 142 & & 76 & 36 & 40 & \\
\hline $2 a-2 b$ & 48 & 17 & 31 & & 38 & 17 & 21 & \\
\hline $3 a-3 c$ & 60 & 26 & 34 & & 52 & 26 & 26 & \\
\hline \multicolumn{2}{|c|}{ Operation time (min) } & $400.8 \pm 116.0$ & $415.6 \pm 118.5$ & 0.3418 & & $400.8 \pm 116.0$ & $425.9 \pm 119.4$ & 0.172 \\
\hline Intraoperative & & & & & & & & \\
\hline blood loss (ml) & & $233.3 \pm 388.3$ & $163.0 \pm 350.1$ & 0.1421 & & $233.3 \pm 388.3$ & $240.6 \pm 486.0$ & 0.915 \\
\hline Albumin (g/dl) & & $3.28 \pm 0.48$ & $4.21 \pm 0.34$ & $<0.0001$ & & $3.28 \pm 0.48$ & $4.21 \pm 0.36$ & $<0.001$ \\
\hline CRP (mg/l) & & $0.682 \pm 1.234$ & $0.188 \pm 0.555$ & $<0.0001$ & & $0.682 \pm 1.234$ & $0.191 \pm 0.481$ & $<0.001$ \\
\hline
\end{tabular}


Table 3 Relationships between PNI and clinicopathological features in gastric cancer patients with normal serum CEA levels before and after propensity score matching (Continued)

\begin{tabular}{|c|c|c|c|c|c|c|c|c|}
\hline \multirow{4}{*}{ Characteristics } & \multirow{4}{*}{$\begin{array}{l}\text { Total } \\
\text { patients }\end{array}$} & \multirow{2}{*}{\multicolumn{3}{|c|}{$\begin{array}{l}\text { All patients } \\
\mathrm{PNI}\end{array}$}} & \multirow{4}{*}{$\begin{array}{l}\text { Total } \\
\text { patients }\end{array}$} & \multirow{2}{*}{\multicolumn{3}{|c|}{$\begin{array}{l}\text { Propensity matched patients } \\
\text { PNI }\end{array}$}} \\
\hline & & & & & & & & \\
\hline & & $<44.3$ & $\geq 44.3$ & & & $<44.3$ & $\geq 44.3$ & \\
\hline & & $(n=79)$ & $(n=207)$ & $p$ value & & $(n=79)$ & $(n=87)$ & $p$ value \\
\hline \multicolumn{2}{|c|}{ Adjuvant chemotherapy } & & & 0.4396 & & & & 0.099 \\
\hline Yes & 74 & 23 & 51 & & 59 & 23 & 36 & \\
\hline No & 212 & 56 & 156 & & 107 & 56 & 51 & \\
\hline
\end{tabular}

differ significantly between the low and high PNI groups. Finally, 79 low PNI patients and 87 high PNI patients were selected for analysis.

\section{Cox regression analysis of CSS in the propensity score matched patients with normal preoperative serum CEA levels}

In the univariate analysis, pStage $(p<0.001)$, and PNI $(p=0.030)$, were significantly associated with CSS. In the multivariate analysis, pStage (HR: 7.803, 95\% CI: 3.015-24.041; $p<0.001$ ) and PNI (HR: 3.078, 95\% CI: $1.232-8.707 ; p=0.016)$ were identified as independent prognostic factors of CSS (Table 4).

\section{Survival analysis stratified by the PNI in the propensity score matched patients with normal preoperative serum CEA levels}

The Kaplan-Meier analysis and log-rank test demonstrated that patients with a low PNI value had a significantly poorer CSS than those with a high PNI value $(p=0.011$; Fig. 5$)$.

\section{Discussion}

Diagnostic imaging modalities and several tumor markers, including preoperative ou. However, gastric cancer patients do not always have elevated serum CEA levels, even in advanced cases [12]. Moreover, serum
CEA levels are more commonly used for postoperative surveillance. However, it cannot be expected to serve as a surrogate marker for cancer recurrence when the primary tumor exhibits normal serum CEA levels [13]. Therefore, in this study, we focused on the significance of the PNI as a potential predictor of survival in gastric cancer patients with normal preoperative serum CEA levels.

The PNI was initially developed to predict perioperative complications, such as anastomotic leakage, delayed tissue repair, and the length of postoperative hospital stay [9]. Recently, however, accumulating evidence suggests that the preoperative PNI could be a favorable prognostic factor and a more reliable assessment tool for the physiological status of cancer patients [14-16]. Albumin is a widely used nutritional parameter, and produced by hepatocytes and is regulated by proinflammatory cytokines, including inteleukin-1 (IL-1), IL-6, and tumor necrosis factor- $\alpha$ (TNF- $\alpha$ ) that adversely affect catabolic metabolism. These proinflammatory cytokines are produced by the tumor itself or the host and play crucial roles in carcinogenesis, cancer progression, and neoangiogenesis [17, 18]. Similarly, lymphocytes are a fundamental component of the cytotoxic immune response that suppresses tumor cell proliferation and invasion via cytokine-mediated cytotoxicity $[19,20]$. Hence, the PNI may represent a

Table 4 Univariate and multivariate analyses to assess the prognostic factors in propensity score matched 166 gastric cancer patients with normal serum CEA levels

\begin{tabular}{|c|c|c|c|c|c|c|c|}
\hline \multirow[t]{2}{*}{ Variables } & & \multicolumn{3}{|c|}{ Univariate analysis } & \multicolumn{3}{|c|}{ Multivariate analysis } \\
\hline & & $\mathrm{HR}$ & $95 \% \mathrm{Cl}$ & $p$ value & $\mathrm{HR}$ & $95 \% \mathrm{Cl}$ & $p$ value \\
\hline Gender & female / male & 0.652 & $0.230-1.631$ & 0.370 & & & \\
\hline pStage & I, II / III & 7.303 & $2.827-22.468$ & $<0.001$ & 7.803 & $3.015-24.041$ & $<0.001$ \\
\hline Tumor size & $<5 / \geq 5$ & 1.735 & $0.710-4.618$ & 0.230 & & & \\
\hline PNI & $\geq 44.3 /<44.3$ & 2.742 & $1.100-7.745$ & 0.030 & 3.078 & $1.232-8.707$ & 0.016 \\
\hline Diff. & well \& mod / poor & 1.588 & $0.657-4.054$ & 0.306 & & & \\
\hline $\mathrm{BMI}$ & $\geq 18.5 /<18.5$ & 1.050 & $0.245-3.125$ & 0.939 & & & \\
\hline Adjuvant & No / Yes & 2.419 & $1.000-6.179$ & 0.050 & & & \\
\hline
\end{tabular}

HR Hazard ratio, Cl Confidence interval, PNI Prognostic nutritional index, CEA Carcinoembryonic antigen, pStage Pathological Stage, Diff Differentiation, BMI Body mass index, Adjuvant adjuvant chemotherapy 


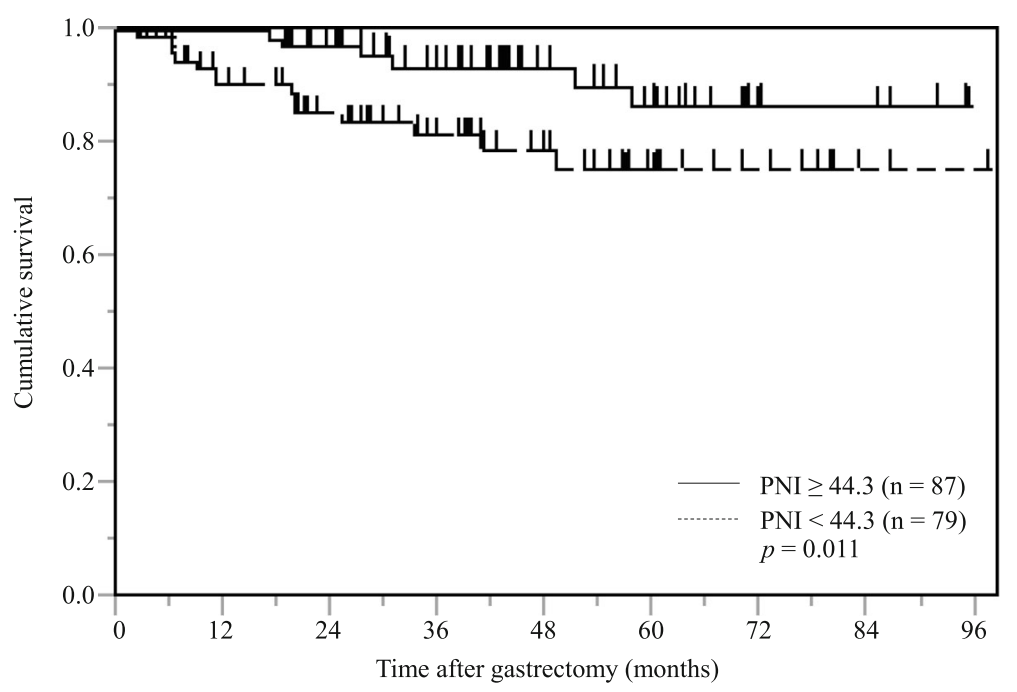

Fig. 5 Kaplan-Meier curves of postoperative cancer-specific survival based on PNI in propensity score matched 166 gastric cancer patients with normal serum CEA levels

comprehensive indicator of the long-term prognosis of cancer patients.

First, we analyzed the associations between PNI values and the clinicopathological characteristics of 368 patients who underwent curative laparoscopicassisted gastrectomy for Stage IA-IIIC gastric cancer. We demonstrated that a low preoperative PNI value was associated with age, BMI, white and red blood cell counts, a large tumor size, deep invasion, lymph node metastasis, an advanced pStage, lower albumin concentrations, and higher C-reactive protein levels, but not preoperative serum CEA levels. Our findings support the hypothesis that a low PNI value is indicative of chronic inflammation and malnutrition in patients with more aggressive or advanced cancers. In light of the significance of preoperative PNI values on survival, Kaplan-Meier analysis of the 368 patients in the entire cohort demonstrated that a low PNI value was associated with a significantly poorer CSS. In the multivariate analysis, a low PNI value was also confirmed to be a significant independent predictor of poor CSS. However, the precise mechanism underlying the association between PNI values and CSS has not been fully elucidated. On the other hand, several previous studies have reported that cancer patients experiencing postoperative complications generally have a poorer prognosis [21-23]. Because patients with a low preoperative PNI value are at a high risk of postoperative complications, the preoperative PNI value may affect both postoperative short- and longterm outcomes.

CEA is a glycoprotein attached to the surface of enterocytes, with a weight of $200 \mathrm{kDa}$ and a role in programmed cell death and cell adhesion [24]. Although
CEA is one of the most widely and frequently used tumor markers, especially in gastrointestinal cancer, its exact function in cancer screening, diagnosis, treatment decision-making, and postoperative surveillance remains poorly understood. Therefore, we evaluated the utility of the PNI as a predictor of survival in gastric cancer patients with normal preoperative serum CEA levels. We revealed that a low preoperative PNI value was a comprehensive indicator of cancer-related inflammation and a poor nutritional status in patients with normal serum CEA levels. Furthermore, the multivariate analysis demonstrated that a low PNI value was independently associated with a poor prognosis. These findings reflect the widely accepted hypothesis that the long-term outcome of cancer patients is not determined by tumor characteristics alone, but is also associated with cancer-related inflammation and malnutrition. In addition, several studies have reported that feasibility of adjuvant chemotherapy was defined by perioperative nutritional condition. Similarly, our result showed the ratio of feasibility of adjuvant chemotherapy is low in malnourished patients. Therefore, early pre- and post-operative nutritional support, through enteral feeds, early oral intake or intravenous feeding, has become an increasingly standard element of enhanced recovery care pathways following gastrectomy [25].

The significance of the PNI in cancer patients has not been uniformly confirmed, because the optimal cutoff point for the PNI in predicting postoperative survival remains controversial [26-28]. Thus, one of the aims of our study was to elucidate the optimal cutoff point of the preoperative PNI for predicting CSS in patients with gastric cancer. Based on receiver operating characteristic curve analysis of the 368 patients who had undergone 
curative gastrectomy, we determined an optimal cutoff value for the PNI of 44.3. This was remarkably close to the standard value of 45, reported by Onodera et al. [9], at which gastrointestinal anastomosis could be performed safely.

Our study has several limitations that need to be acknowledged. These include its uncontrolled and retrospective nature, single institutional design, relatively small sample size, and short follow-up period. Moreover, we excluded patients who had undergone neoadjuvant chemotherapy. Additionally, we focused on the preoperative PNI, but failed to evaluate dynamic changes in PNI values during the clinical course of the disease. Finally, the biological mechanisms associated with systemic inflammation and prognosis have yet to be elucidated. Therefore, further large-scale prospective studies are needed to determine the molecular mechanisms linking a low PNI value with a poorer prognosis in patients with gastric cancer.

Despite these limitations, we showed that a low preoperative PNI value is a potential independent risk factor for a poor prognosis in patients with gastric cancer, even in those with normal serum CEA levels. These results may be useful when considering the clinical decisionmaking process in gastric cancer patients with a low PNI.

\section{Conclusions}

In this study, we confirmed that the PNI was associated with the CSS of gastric cancer patients after curative gastrectomy. It is particularly noteworthy that a low preoperative PNI value is a potential independent risk factor for poorer CSS in patients with gastric cancer, even in those with normal serum CEA levels. The PNI is convenient, cost effective and readily available, it could act as a marker of survival in gastric cancer. We offer evidence to show that an accessible parameter like PNI can help clinicians detect signs of recurrence very early and effectively customize treatment regimens.

\footnotetext{
Abbreviations

Adjuvant: Adjuvant chemotherapy; BMl: Body mass index; CEA: Carcinoembryonic antigen; Cl: Confidence interval; CRP: C-reactive protein; CSS: Cancer-specific survival; Diff: Differentiation; EGJ: Esophagogastric junction; HR: Hazard ratio; L: Lower; L(A)DG: Laparoscopic (assisted) distal gastrectomy; LPG: Laparoscopic proximal gastrectomy; LTG: Laparoscopic total gastrectomy; M: Middle; PNI: Prognostic nutritional index; pStage: Pathological Stage; RBC: Red blood cell; U: Upper; WBC: White blood cell
}

\section{Acknowledgements}

None.

\section{Funding}

None.

\section{Availability of data and materials}

The datasets during and/or analyzed during the current study available from the corresponding author on reasonable request.

\section{Authors' contributions}

$\mathrm{NH}$ was the lead author, and conceived this study. YK, YF, SK, TY, RH and TT collected data, performed analysis, and drafted the manuscript. YT reviewed paper and technique of surgery. All authors read and approved the final manuscript.

\section{Ethics approval and consent to participate}

This retrospective study was approved with the ethical board of Shimane University Faculty of Medicine, and was conducted in accordance with the Declaration of Helsinki. Informed consent was obtained from all individual participants included in the study.

\section{Consent for publication}

Not applicable.

\section{Competing interests}

The authors declare that they have no competing interests.

\section{Publisher's Note}

Springer Nature remains neutral with regard to jurisdictional claims in published maps and institutional affiliations.

Received: 21 September 2017 Accepted: 8 March 2018

Published online: 13 March 2018

\section{References}

1. Hirahara N, Matsubara T, Mizota Y, Ishibashi S, Tajima Y. Prognostic value of preoperative inflammatory response biomarkers in patients with esophageal cancer who undergo a curative thoracoscopic esophagectomy. BMC Surg. 2016;20(16(1)):66. https://doi.org/10.1186/s12893-016-0179-5.

2. Mimatsu K, Fukino N, Ogasawara Y, Saino Y, Oida T. Utility of Inflammatory Marker- and Nutritional Status-based Prognostic Factors for Predicting the Prognosis of Stage IV Gastric Cancer Patients Undergoing Non-curative Surgery. Anticancer Res. 2017;37(8):4215-22.

3. Lin YH, Chang KP, Lin YS, Chang TS. Pretreatment combination of platelet counts and neutrophil-lymphocyte ratio predicts survival of nasopharyngeal cancer patients receiving intensity-modulated radiotherapy. Onco Targets Ther. 2017;10:2751-60. https://doi.org/10.2147/OTT.S137000. eCollection 2017.

4. Kim A, Im M, Ma JY. Sosiho-tang ameliorates cachexia-related symptoms in mice bearing colon 26 adenocarcinoma by reducing systemic inflammation and muscle loss. Oncol Rep. 2016;35(3):1841-50. https://doi.org/10.3892/or. 2015.4527. Epub 2015 Dec 28

5. Dev R, Wong A, Hui D, Bruera E. The Evolving Approach to Management of Cancer Cachexia. Oncology (Williston Park). 2017;31(1):23-32.

6. Wang $Y$, Wang $Y$, Mu H, Liu T, Chen $X$, Shen Z. Enhanced specific antitumor immunity of dendritic cells transduced with the glypican 3 gene and cocultured with cytokine-induced killer cells against hepatocellular carcinoma cells. Mol Med Rep. 2015;11(5):3361-7. https://doi.org/10.3892/mmr.2015.3239.

7. Hirahara N, Matsubara T, Hayashi H, Takai K, Fujii Y, Tajima Y. Impact of inflammation-based prognostic score on survival after curative thoracoscopic esophagectomy for esophageal cancer. Eur I Surg Oncol. 2015;41(10):1308-15. https://doi.org/10.1016/j.ejso.2015.07.008.

8. Song A, Eo W, Lee S. Comparison of selected inflammation-based prognostic markers in relapsed or refractory metastatic colorectal cancer patients. World J Gastroenterol. 2015;21(43):12410-20. https://doi.org/10. 3748/wjg.v21.i43.12410.

9. Onodera T, Goseki N, Kosaki G. Prognostic nutritional index in gastrointestinal surgery of malnourished cancer patients [in Japanese]. Nihon Geka Gakkai Zasshi. 1984:85:1001-5.

10. Japanese Gastric Cancer Association. Japanese gastriccancer treatment guidelines 2010 (ver.3). Gastric Cancer. 2011;14:113-23.

11. Sobin L, Gospodarowicz M, Wittekind C, editors. International Union against Cancer (UICC). TNM classification of malignant tumors, $7^{\text {th }}$ ed. New York: Wiley-Blackwell; 2010.

12. Chen C, Chen Q, Zhao Q, Liu M, Guo J. Value of Combined Detection of Serum CEA, CA72-4, CA19-9, CA15-3 and CA12-5 in the Diagnosis of Gastric Cancer. Ann Clin Lab Sci. 2017;47(3):260-3.

13. Ohashi T, Komatsu S, Ichikawa D, Kosuga T, Okamoto K, Arita T, et al. Monitoring with sensitive tumor markers contributes to decision-making and better prognosis in gastric cancer patients with peritoneal recurrence. Int J Clin Oncol. 2017; https://doi.org/10.1007/s10147-017-1132-z. 
14. Shimizu K, Okita R, Saisho S, Maeda A, Nojima Y, Nakata M. Preoperative neutrophil/lymphocyte ratio and prognostic nutritional index predict survival in patients with non-small cell lung cancer. World J Surg Oncol. 2015;13:291. https://doi.org/10.1186/s12957-015-0710-7.

15. Okamura Y, Ashida R, Ito T, Sugiura T, Mori K, Uesaka K. Preoperative neutrophil to lymphocyte ratio and prognostic nutritional index predict overall survival after hepatectomy for hepatocellular carcinoma. World J Surg. 2015;39(6):1501-9. https://doi.org/10.1007/s00268-015-2982-z.

16. Ikeguchi M, Urushibara S, Shimoda R, Yamamoto M, Maeda Y, Ashida K. Inflammation-based prognostic scores and nutritional prognostic index in patients with locally-advanced unresectable colorectal cancer. World J Surg. 2014;12:210. https://doi.org/10.1186/1477-7819-12-210.

17. Balkwill F. Tumour necrosis factor and cancer. Nat Rev Cancer. 2009:9:36171. https://doi.org/10.1038/nrc2628.

18. Brenner D, Blaser H, Mak TW. Regulation of tumour necrosis factor signalling: live or let die. Nat Rev Immunol. 2015;15:362-74. https://doi.org/ 10.1038/nri3834.

19. Gupta D, Lis CG. Pretreatment serum albumin as a predictor of cancer survival: a systematic review of the epidemiological literature. Nutr J. 2010;9: 69. https://doi.org/10.1186/1475-2891-9-69.

20. Ray-Coquard I, Cropet C, Van Glabbeke M, Sebban C, Le Cesne A, Judson I, et al. Lymphopenia as a prognostic factor for overall survival in advanced carcinomas, sarcomas, and lymphomas. Cancer Res. 2009;69:5383-91. https://doi.org/10.1158/0008-5472.CAN-08-3845.

21. Aoyama T, Murakawa M, Katayama Y, Yamaoku K, Kanazawa A, Higuchi A, et al. Impact of postoperative complications on sutvival and recurrence inpancreatic cancer. Anticancer Res. 2015;35(4):2401-9.

22. Kulu Y, Tarantio I, Warschkow R, Kny S, Schneider M, Schmied BM, et al. Anastomotic leakage is associated with impaired overall and disease-free survival after curative rectal cancer resction: a propensity score analysis. Ann Surg Oncol. 2015;22(6):2059-67. https://doi.org/10.1245/s10434-014-4187-3.

23. Tokunaga M, Tanizawa Y, Bando E, Kawamura T, Terashima M. Poor survival rate in patients with postoperative intra-abdominal infectious complications following curative gastrectomy for gastric cancer. Ann Surg Oncol. 2013;20: 1575-83. https://doi.org/10.1245/s10434-012-2720-9.

24. Téllez-Avila Fl, García-Osogobio SM. The carcinoembryonic antigen: apropos of an old friend. Rev Investig Clin. 2005;57(6):814-9.

25. Wong-Chong N, Kehlet H, Grantcharov TP. Outcomes From an Enhanced Recovery Program for Laparoscopic Gastric Surgery. Surg Laparosc Endosc Percutan Tech. 2016;26(3):e50-5. https://doi.org/10.1097/SLE. 0000000000000277.

26. Sakurai K, Ohira M, Tamura T, Toyokawa T, Amano R, Kubo N, et al. Predictive potential of preoperative nutritional status in long-term outcome projections for patients with gastric cancer. Ann Surg Oncol. 2015;23(2):525-33.

27. Miao J, Xiao W, Wang L, Han F, Wu H, Deng X, et al. The value of the Prognostic Nutritional Index (PNI) in predicting outcomes and guiding the treatment strategy of nasopharyngeal carcinoma (NPC) patients receiving intensity-modulated radiotherapy (IMRT) with or without chemotherapy. Cancer Res Clin Oncol. 2017;143(7):1263-73. https://doi.org/10.1007/s00432017-2360-3.

28. Chen S, Yang X, Feng JF. A novel inflammation-based prognostic score for patients with esophageal squamous cell carcinoma: the c-reactive protein/ prognostic nutritional index ratio. Oncotarget 2016;7(38):62123-62132. doi: https://doi.org/10.18632/oncotarget.113

\section{Submit your next manuscript to BioMed Central and we will help you at every step:}

- We accept pre-submission inquiries

- Our selector tool helps you to find the most relevant journal

- We provide round the clock customer support

- Convenient online submission

- Thorough peer review

- Inclusion in PubMed and all major indexing services

- Maximum visibility for your research

Submit your manuscript at www.biomedcentral.com/submit 